\title{
Clinical Reasoning: A Middle-aged Man With Progressive Gait Abnormalities
}

Junyu Lin, MD, * Yanbing Hou, MD, * and Huifang Shang, MD

Neurology ${ }^{\circledR}$ 2021;97:e2423-e2428. doi:10.1212/WNL.0000000000012756
Correspondence

Dr. Shang

hfshang2002@126.com

MORE ONLINE

Video

*These authors contributed equally to this work.

From the Department of Neurology, West China Hospital, Sichuan University, Chengdu, China.

Go to Neurology.org/N for full disclosures. Funding information and disclosures deemed relevant by the authors, if any, are provided at the end of the article. 


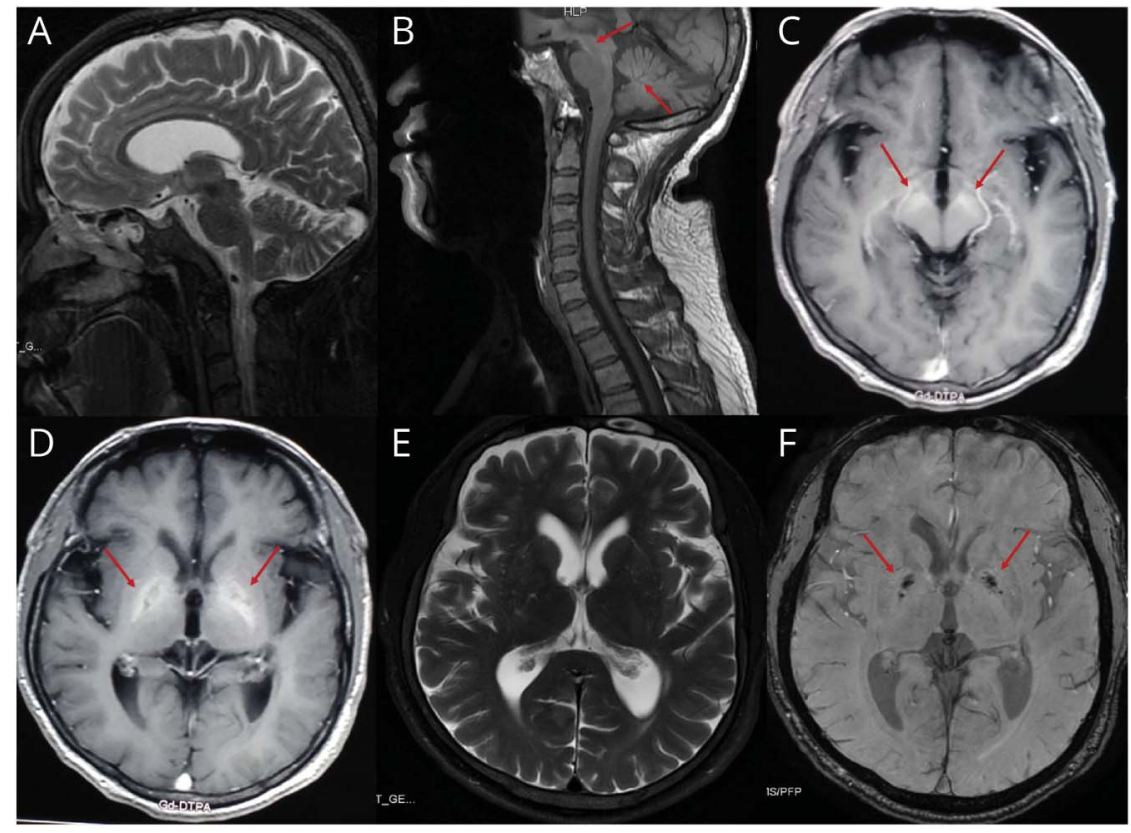

(A) Sagittal T2-weighted MRI findings show thin corpus callosum; (B-C) T1-weighted images show hyperintense signals in the mesencephalon, pons, and cerebellum (red arrows); (D) T1-weighted image shows the bilateral symmetrical hyperintense signal in the basal ganglia (red arrows); (E) T2-weighted image shows no abnormal signal in the basal ganglia; and (F) SWI shows the bilateral symmetrical hypointense signal in the globus pallidus (red arrows).

\section{Section 1}

A 51-year-old Chinese man presented with progressive gait disturbance for 18 months. Eighteen months earlier, he developed mild spasticity and weakness of the lower limbs when walking. His symptoms exacerbated gradually, and he developed unsteady and shuffling gait 1 year ago, accompanied by bradykinesia of the limbs. He occasionally experienced urinary incontinence without bowel symptoms in the past 6 months. He had a 7-year history of hypertension and alcoholic liver cirrhosis and underwent transjugular intrahepatic portosystemic shunt (TIPS) 2 years earlier due to bleeding esophageal varices. He had a 20-year history of alcohol use and no history of smoking and toxins exposure. He came from a nonconsanguineous family with no remarkable family history. A local hospital initially diagnosed hereditary spastic paraplegia (HSP). Subsequently, he was referred to our department. Brain magnetic resonance imaging (MRI) in the local hospital demonstrated thin corpus callosum (TCC) (Figure 1A). Neurologic examination revealed mild dysarthria, horizontal gaze-evoked nystagmus, normal muscle bulk and strength, bradykinesia and lead-pipe rigidity of the left upper limb, spasticity of the lower limbs, diffuse hyperreflexia, ankle clonus, extensor plantar responses, impaired vibration sensation in the left lower limb, limb ataxia during finger-to-nose and heel-toshin tests, difficulty in tandem walking, and a spastic, widebased, and shuffling gait, but no tremor or postural instability (Video 1, http://links.lww.com/WNL/B519). The Montreal Cognitive Assessment (MoCA) score was 21/30 (naming, 1; attention, 2; abstraction, 1; language, 1; and delay recall, 4).

\section{Questions for Consideration:}

1. Can a HSP diagnosis explain all symptoms of the patient?

2. Which subtype of HSP was most likely?

\section{GO TO SECTION 2}




\section{Section 2}

The patient presented with middle-age onset of spasticityataxia-parkinsonism syndrome with predominantly progressive spastic paraplegia. HSPs are a group of monogenic disorders characterized pathologically by degeneration of the corticospinal tract and dorsal column and clinically by progressive spastic paraplegia accompanied occasionally by impaired vibration sensation and urinary incontinence. In addition, complicated HSP may have other neurologic features such as ataxia, dysarthria, neuropathy, and parkinsonism syndrome. ${ }^{1}$ HSP-TCC, a subtype of complicated HSP, exhibits progressive spastic paraparesis with extrapyramidal symptoms, cognitive impairment, and TCC, similar to our patient. SPG11 and SPG15 are the most common causative genes for HSP-TCC. ${ }^{1}$

\section{Questions for Consideration:}

1. What examinations are required?

2. What other causes should be considered?

GO TO SECTION 3 


\section{Section 3}

Up to 79 HSP genes have been identified, including autosomal dominant, autosomal recessive, and X-linked. Therefore, a gene panel for HSP was chosen. However, no pathogenic mutations were revealed. Although additional genes associated with HSP still need to be identified, the negative family history, nonconsanguineous parents, and a relatively late age at onset suggest acquired causes rather than genetic HSP. ${ }^{1}$ Structural, vascular, inflammatory, infectious, metabolic, toxic, neurodegenerative, and iatrogenic causes can all result in acquired spastic paraplegia. Therefore, additional examinations were conducted. Besides decreased albumin $(31 \mathrm{~g} / \mathrm{L}$, normal: $40-55 \mathrm{~g} / \mathrm{L})$ and increased direct bilirubin $(10.2 \mu \mathrm{mol} / \mathrm{L}$, normal: $0-8.0 \mu \mathrm{mol} / \mathrm{L}$ ), other parameters, including serum electrolytes, ferritin, folate, homocysteine, vitamin B12, vitamin E, copper, ceruloplasmin, liver enzymes, kidney functions, and CSF, were normal. HIV and syphilis test results were negative. Kayser-Fleischer (K-F) ring and retinal degeneration were absent. Electromyogram finding was normal. Brain MRI was reexamined. Besides TCC, hyperintensities in the bilateral basal ganglia, mesencephalon, pons, and cerebellum on T1-weighted images and hypointensity in the bilateral globus pallidus on susceptibility-weighted imaging (SWI) with normal T2 images were found (Figure 1B-F). Spinal cord MRI and brain CT findings were normal.

\section{Questions for Consideration:}

1. What do the brain abnormal signals signify?

2. What disease should be considered? 


\section{Section 4}

SWI hypointensity indicates paramagnetic brain deposits such as copper, iron, calcium, and manganese. As a reversible disease, Wilson disease (WD) caused by ATP7B mutations was first considered. Extrapyramidal, pyramidal, psychiatric symptoms, and abnormal liver function may occur in WD along with T1 hyperintensity and SWI hypointensity in the lenticular nucleus, which was consistent with our patient. However, the most characteristic imaging feature of WD is the concurrence of hyperintense and hypointense signals on T2weighted images, ${ }^{2}$ which was absent in our patient. Normal serum ceruloplasmin and absence of K-F ring also excluded WD.

Iron is another paramagnetic substance easily deposited in the brain. Neurodegeneration with brain iron accumulation (NBIA) is a group of genetically heterogeneous disorders. ${ }^{3}$ FA2H can cause diverse phenotypes, including HSP type 35, leukodystrophy, and NBIA, leading to complex neuropsychiatric symptoms. $\mathrm{FA} 2 \mathrm{H}$-associated neurodegeneration (FAHN) fits best with our patient's phenotype. The characteristic MRI findings of FAHN can be summarized by the acronym "WHAT": white matter changes, T2 hypointensity in the basal ganglia, pontocerebellar atrophy, and TCC. ${ }^{4}$ Despite the overlapping clinical symptoms, TCC, and SWI characteristics, the distinctive T2 hypointensity of iron accumulation was absent in our patient. Moreover, the age at onset of FAHN is much younger.

Basal ganglia calcification can cause neuropsychological, cognitive, and movement disorders. It can be primary when caused by heterozygous mutations of SLC20A2, PDGFRB, $P D G F B$, and XPR1 and homozygotic or compound heterozygous mutations of MYORG and JAM2. ${ }^{5}$ Various conditions can cause secondary basal ganglia calcification, most commonly parathyroid disturbances related to metabolic dysfunctions of calcium/phosphorus. ${ }^{6}$ Hyperintensities on T1-weighted and $\mathrm{T} 2$-weighted images and hypointensities on SWI were observed in brain calcification. However, the absence of hyperdensity on the CT scan excluded calcification in our patient.

Manganese deposition in the brain shows $\mathrm{T} 1$ hyperintensity and SWI hypointensity mainly in the globus pallidus with normal T2 images, concordant with our patient. Manganese deposition can be inherited, through mutations of the manganese transporter genes including SLC3OA10 and SLC39A14, ${ }^{7}$ or acquired from environmental overexposure to manganese and impairment of manganese excretion in chronic liver disease. Patients with chronic liver disease or portosystemic shunts may develop neurologic syndromes, such as acquired hepatocerebral degeneration (AHD) and hepatic myelopathy (HM), characterized by extrapyramidal symptoms and spastic paraplegia, respectively. ${ }^{8}$ Impaired vibration sensation and urinary incontinence can also occur in some patients with HM. Although spinal cord demyelination has been detected in autopsy, spinal cord MRI is usually normal in those with HM. The neuroimaging findings, clinical symptoms, and medical history of alcoholic liver cirrhosis and TIPS raised a strong suspicion of AHD and HM in our patient. Furthermore, we found an increased blood ammonia level $(210.8 \mu \mathrm{mol} / \mathrm{L}$, normal: 9.0$30.0 \mu \mathrm{mol} / \mathrm{L}$ ) and diffuse slow-wave activity in EEG, consistent with the characteristics of AHD and HM.,10 To exclude potential genetic causes, we performed whole-exome sequencing, and no mutation was found. The patient reported experiencing episodes of hepatic encephalopathy twice after TIPS. Therefore, concurrent $\mathrm{AHD}$ and $\mathrm{HM}$ were diagnosed.

\section{Questions for Consideration:}

1. What treatments are indicated?

2. How to explain the TCC?

GO TO SECTION 5 


\section{Section 5}

Although the pathogeneses of AHD and HM remain unclear, portacaval shunts or less commonly splenorenal shunts may play important roles even in the absence of liver dysfunction. After portosystemic shunting, toxic metabolites, particularly manganese and ammonia, cannot be removed by the hepatobiliary system, causing deposition in the brain and spinal cord, with subsequent neurodegeneration. Ammoniareducing treatment may be beneficial in treating AHD and HM. The condition of our patient improved slightly with ammonia-reducing treatment by L-ornithine-L-aspartate. Limb rigidity and spasticity showed mild response to pramipexole and baclofen. Although efficacy of liver transplantation has been shown in some cases, ${ }^{10}$ our patient declined it. At the 1-year follow-up, despite slightly decreased muscle strength of the right lower limb, he still walked unaided (Video 1).

Considering alcoholism history and TCC, concomitant Marchiafava-Bignami disease (MBD) was considered for the patient. MBD is a complication of alcohol abuse characterized pathologically by demyelination and atrophy of corpus callosum and clinically by epilepsy, cognitive decline, impaired walking, dysarthria, and pyramidal signs. ${ }^{11}$ A previous research found lesions in corpus callosum of $27.9 \%$ patients with MBD, disappeared during the follow-up, and only $20.9 \%$ patients with MBD experienced seizures. ${ }^{11}$ Therefore, TCC in our patient might also ascribe to a possible concomitant MBD, irrespective of the absence of abnormal signals in the MRI and EEG.

\section{Discussion}

Both AHD and HM are rare complications of cirrhotic liver disease, ${ }^{9,10}$ and their combination has been previously reported. ${ }^{12}$ Both have poor prognosis with mostly irreversible neurologic deficits. A previous study on 16 patients with AHD or HM found 12 patients who had died while awaiting for liver transplantation during a median follow-up of 29 months. ${ }^{10}$ Liver transplantation in the early stage is the only effective treatment to reverse neurologic impairments and improve survival. Therefore, early recognition of AHD or HM is critical. As shown in the case, the presence of extrapyramidal symptoms or progressive spastic paraplegia, a precondition of portosystemic shunts in combination with a characteristic neuroimaging picture of abnormal signal mainly in the globus pallidus, namely, T1 hyperintensity and SWI hypointensity, is a strong indicator of AHD or HM.

Another important takehome lesson is that cognitive bias can influence clinicians' judgment on differential diagnosis. In this patient, the initial suspicion of complex HSP was guided by the complex symptoms and TCC; consequently, we focused on this rather than the less "exciting" explanation of cirrhosis. Therefore, being rational and logical is important in clinical practice. For instance, in patients with progressive spastic paraplegia, acquired causes, especially curable causes, should always be excluded first. In the absence of a pathogenic HSP mutation in a patient with spastic paraplegia, a new genetic mutation should only be assumed after a comprehensive examination ruling out acquired causes.

\section{Acknowledgment}

The authors thank the patient for participating in this study.

\section{Study Funding}

1.3.5 project for disciplines of excellence, West China Hospital, Sichuan University (Grant No. ZYJC18038).

\section{Disclosure}

$\mathrm{J}$ Lin, Y Hou, and $\mathrm{H}$ Shang report no disclosures relevant to the manuscript. Go to Neurology.org/ $\mathrm{N}$ for full disclosures.

\begin{tabular}{lll}
\multicolumn{2}{l}{ Appendix Authors } \\
\hline Name & Location & Contribution \\
\hline $\begin{array}{l}\text { Junyu } \\
\text { Lin, MD }\end{array}$ & $\begin{array}{l}\text { West China Hospital, } \\
\text { Sichuan University, } \\
\text { Chengdu, China }\end{array}$ & $\begin{array}{l}\text { Study design and } \\
\text { conceptualization, drafted and } \\
\text { revised the article, and analyzed } \\
\text { and interpreted data }\end{array}$ \\
\hline $\begin{array}{l}\text { Yanbing } \\
\text { Hou, MD }\end{array}$ & $\begin{array}{l}\text { West China Hospital, } \\
\text { Sichuan University, } \\
\text { Chengdu, China }\end{array}$ & $\begin{array}{l}\text { Revised the article and } \\
\text { interpreted the data }\end{array}$ \\
$\begin{array}{l}\text { Huifang } \\
\text { Shang, } \\
\text { MD }\end{array}$ & $\begin{array}{l}\text { West China Hospital, } \\
\text { Sichuan University, } \\
\text { Chengdu, China }\end{array}$ & $\begin{array}{l}\text { Revised the article and approved } \\
\text { all final changes }\end{array}$ \\
\hline
\end{tabular}

\section{References}

1. Shribman S, Reid E, Crosby AH, Houlden H, Warner TT. Hereditary spastic paraplegia: from diagnosis to emerging therapeutic approaches. Lancet Neurol. 2019; 18(12):1136-1146.

2. Zhong W, Huang Z, Tang X. A study of brain MRI characteristics and clinical features in 76 cases of Wilson's disease. J Clin Neurosci. 2019;59:167-174.

3. Schneider SA, Hardy J, Bhatia KP. Syndromes of neurodegeneration with brain iron accumulation (NBIA): an update on clinical presentations, histological and genetic underpinnings, and treatment considerations. Mov Disord. 2012;27(1):42-53.

4. Rattay TW, Lindig T, Baets J, et al. FAHN/SPG35: a narrow phenotypic spectrum across disease classifications. Brain. 2019;142(6):1561-1572.

5. Cen Z, Chen Y, Chen S, et al. Biallelic loss-of-function mutations in JAM2 cause primary familial brain calcification. Brain. 2020;143(2):491-502.

6. Saleem S, Aslam HM, Anwar M, et al. Fahr's syndrome: literature review of current evidence. Orphanet J Rare Dis. 2013;8:156.

7. Mukhopadhyay S. Familial manganese-induced neurotoxicity due to mutations in SLC30A10 or SLC39A14. Neurotoxicology. 2018;64:278-283.

8. Ciarlariello V, Fujino M, Almeida M, Barsottini O, Pedroso JJN. Teaching Video NeuroImages: hepatic myelopathy: an unusual neurologic complication of hepatic encephalopathy. Neurology. 2019;93(3):e320-e321.

9. Fernandez-Rodriguez R, Contreras A, De Villoria JG, Grandas F. Acquired hepatocerebral degeneration: clinical characteristics and MRI findings. Eur J Neurol. 2010; 17(12):1463-1470.

10. Pinarbasi B, Kaymakoglu S, Matur Z, et al. Are acquired hepatocerebral degeneration and hepatic myelopathy reversible?. J Clin Gastroenterol. 2009;43(2):176-181.

11. Hillbom M, Saloheimo P, Fujioka S, Wszolek ZK, Juvela S, Leone MA. Diagnosis and management of Marchiafava-Bignami disease: a review of CT/MRI confirmed cases. J Neurol Neurosurg Psychiatry. 2014;85(2):168-173.

12. Lewis MB, MacQuillan G, Bamford JM, Howdle PD. Delayed myelopathic presentation of the acquired hepatocerebral degeneration syndrome. Neurology. 2000; 54(4):1011. 


\section{Neurology}

Clinical Reasoning: A Middle-aged Man With Progressive Gait Abnormalities

Neurology 2021;97;e2423-e2428 Published Online before print September 9, 2021

DOI 10.1212/WNL.0000000000012756

This information is current as of September 9, 2021

\section{Updated Information \&} Services

References

Subspecialty Collections

Permissions \& Licensing

Reprints including high resolution figures, can be found at: http://n.neurology.org/content/97/24/e2423.full

This article cites 12 articles, 3 of which you can access for free at: http://n.neurology.org/content/97/24/e2423.full\#ref-list-1

This article, along with others on similar topics, appears in the following collection(s):

Basal ganglia

http://n.neurology.org/cgi/collection/basal_ganglia

Gait disorders/ataxia

http://n.neurology.org/cgi/collection/gait_disorders_ataxia MRI

http://n.neurology.org/cgi/collection/mri

Parkinson's disease/Parkinsonism

http://n.neurology.org/cgi/collection/parkinsons_disease_parkinsonism Spastic paraplegia

http://n.neurology.org/cgi/collection/spastic_paraplegia

Information about reproducing this article in parts (figures,tables) or in its entirety can be found online at:

http://www.neurology.org/about/about_the_journal\#permissions

Information about ordering reprints can be found online:

http://n.neurology.org/subscribers/advertise

Neurology ${ }^{\circledR}$ is the official journal of the American Academy of Neurology. Published continuously since 1951, it is now a weekly with 48 issues per year. Copyright @ 2021 American Academy of Neurology. All rights reserved. Print ISSN: 0028-3878. Online ISSN: 1526-632X.

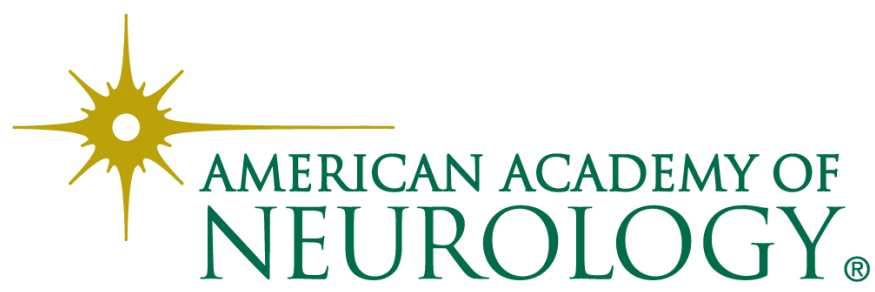

